\title{
LexCult
}

ARTIGOS

\section{INOVAÇÃO CRIATIVA NA EDUCAÇÃO BÁSICA EM TEMPOS DE PANDEMIA DO COVID-19}

\section{CREATIVE INNOVATION IN BASIC EDUCATION IN TIMES OF THE COVID-19 PANDEMIC}

\author{
Fabiano de Caldas Batista ${ }^{1}$ \\ Fabricio Lima ${ }^{2}$ \\ Maria Geralda de Miranda ${ }^{3}$ \\ Reis Friede ${ }^{4}$
}

Resumo: Com a nova realidade escolar, por conta da pandemia do Covid-19, muitas escolas tiveram que se adaptar tecnologicamente e utilizar redes sociais e aplicativos educacionais, para que fosse possível transmitir conteúdos aos alunos. Tal situação imposta, por outro lado, acabou fazendo com que fossem criadas condições para a inovação na forma de ensinar. O presente artigo tem como objetivo apresentar a importância da inovação criativa na Educação Básica e a utilização de ferramentas tecnológicas nas aulas. No que se refere à metodologia, foi feita uma pesquisa de cunho bibliográfico, utilizando-se de artigos encontrados em plataformas de busca acadêmica como Scielo, Google Acadêmico, entre outros. Os descritores utilizados para a busca foram: Educação, tecnologia e pandemia. Após a busca, os artigos foram selecionados e discutidos. Concluiu-se que se vive uma grande mudança, não só no nosso convívio social, por conta da COVID-19, como também na educação, já que professores podem motivar seus alunos, por meio da informática educativa, abandonando velhas metodologias e aceitando a tecnologia como mediadora do processo de ensino-aprendizagem.

Palavras-chave: Inovação. Criatividade. Pandemia. Tecnologia.

\footnotetext{
${ }^{1}$ Mestrando em Desenvolvimento Local pelo Centro Universitário Augusto Mota - UNISUAM no Rio de Janeiro. Especialista em Contabilidade Pública e Auditoria em organizações do setor público. Possui graduação em Ciências Contábeis e Administração.

${ }^{2}$ Graduado em Administração (UNISUL - 2005). Graduando em Pedagogia (UNIASSELVI - 2020). Especializações em Administração de Pessoas, Administração Estratégica, Psicopedagogia, Neuropsicopedagogia, Educação Infantil e Anos Iniciais (UNIASSELVI).

${ }^{3}$ Pós-doutora em Políticas Públicas e Formação Humana pela Universidade do Estado do Rio de Janeiro (UERJ). Pesquisadora do Programa de Pós-graduação em Desenvolvimento Local do Centro Universitário Augusto Motta, UNISUAM, Rio de Janeiro, RJ.

${ }^{4}$ Desembargador Federal. Doutor em Direito pela Universidade Federal do Rio de Janeiro (UFRJ). Mestre em Direito pela Universidade Gama Filho (UGF). Professor e Pesquisador do Programa de Mestrado em Desenvolvimento Local do Centro Universitário Augusto Motta (UNISUAM). E-mail: reisfriede@hotmail.com.
} 
Abstract: With the new school reality, due to the Covid-19 pandemic, many schools had to adapt technologically and use social networks and educational applications, so that it was possible to transmit content to students. Such imposed situations, on the other hand, ended up creating conditions for innovation in the way of teaching. This article aims to present the importance of creative innovation in Basic Education and the use of technological tools in classes. With regard to the methodology, a bibliographic research was carried out, using articles found in academic search platforms such as Scielo, Google Academic, among others. The descriptors used for the search were: Education, technology and pandemic. After the search, the articles were selected and discussed. It was concluded that there is a great change, not only in our social life, due to COVID-19, but also in education, as teachers can motivate their students, through educational computing, abandoning old methodologies and accepting technology as a mediator of the teaching-learning process.

Keywords: Innovation. Creativity. Pandemic. Technology.

Recebido em: 22/07/2021 Aceito em: 10/08/2021 


\section{INTRODUÇÃO}

A educação se configura como um direito fundamental a todos os brasileiros, bem como também, um dever do Estado e da família, garantido por meio da Constituição Federal. Sabe-se que boa parte da infância é vivida na escola e que compete aos professores elaborar fórmulas e arquitetar ideias inovadoras e criativas que possam despertar no aluno o interesse pelo ambiente escolar, onde se sinta motivado. Tal ambiente se configura como sendo para muitos um laboratório de descobertas inovadoras.

É importante fazer uso desse laboratório para que possa chamar a atenção dos alunos com intuito de despertar o conhecimento, por meio da inovação, da criatividade e da curiosidade. Porém, o que se vive atualmente é algo jamais vivido anteriormente, visto que uma pandemia de nível mundial vem disseminando no mundo o medo e a aflição de não poder sair de casa, de ter que se isolar. Com isso, as escolas fecharam suas portas e passaram a se adaptar à nova realidade, para que os alunos não perdessem o foco nos estudos e nos conteúdos semestrais.

Após o aparecimento do novo coronavírus (SARS-CoV-2), foram necessárias as medidas emergenciais e em consequência milhares de alunos ficaram sem aulas devido às recomendações e restrições interpostas por órgãos federativos e organizações mundiais que se uniram em um propósito: combater a proliferação do vírus.

Medidas de isolamento social tornaram-se obrigatórias, a partir de março de 2020 no Brasil, assim, instituições de ensino públicas e privadas tiveram que fechar seus estabelecimentos, como medida preventiva, porém sem nenhum plano estratégico, o que ocasionou pânico pelo alarde das inúmeras informações controversas.

As medidas de isolamento fizeram com que os educadores apresentassem suas aulas por meio de plataformas como Google Classroom, Zoom Cloud Meeting, Whereby, entre outras. Também foram disponibilizados materiais online e videoaulas 
para download. A checagem de presença foi feita da mesma forma, para que se possa acompanhar a frequência de cada aluno.

Em face à nova realidade escolar, percebe-se que o processo de adaptação se configura como um fator de suma importância para a vida em sociedade, e essencial para a efetivação e a realização de seu desenvolvimento. A escolha do presente tema se justifica, já que a construção de uma modalidade de ensino remoto não é apenas uma construção experimental e temporária, para que supra uma necessidade básica, mas uma metodologia de aprendizagem.

\section{CRIATIVIDADE E INOVAÇÃO NA EDUCAÇÃO}

Souza e Pinho (2016) assinalam que em relação à prática didática e pedagógica, o sistema educacional tem passado por amplas modificações. O professor anos atrás apresentava certa "autoridade" em relação aos seus alunos, tendo em vista que este era estimado como sendo o "portador do saber".

É papel fundamental do professor é proporcionar aos seus alunos auxílio na criação de conhecimento, sendo o docente muito importante na estimulação e motivação dos estudantes em sala de aula. O professor é ao mesmo tempo transmissor e receptor de informações e conhecimento (ZWIEREWICZ, 2013).

No entendimento de Cavallo e outros (2016), atualmente existe a necessidade de formar estudantes com embasamento nas requisições profissionais e como cidadão. Pode-se complementar ainda que é de suma importância o senso crítico como ferramenta para esta adaptação.

É necessário que o sujeito possa passar por um sistema educacional, em que possa interagir com os elementos da própria realidade, para que assim, possa melhor adaptar-se a este ambiente. Não se pode haver na formação a abreviação das teorias e ideologias, é necessário que se possa procurar no cotidiano as chaves para a promoção da educação (SILVA, 2013). 
De acordo com Almeida e Lopes (2015), é importante que a tecnologia se apresente como algo frequente e comum aos alunos. Para tanto, o educador deve fazer bom proveito desses recursos para que possa atingir seus objetivos. Deste modo, depara-se com o foco do estudo, isto é, o uso da inovação tecnológica como ferramenta propulsora para o aprendizado com criatividade.

Silveira de Almeida (2018) alude que para que se possa ter um novo método de ensino informatizado, a escola deve capacitar não só seu alunado, mas também seus professores, fazendo com que a proposta pedagógica possa consentir um nível de formação construtiva e participativa.

Cavallo e outros (2016) diz que é necessário, por parte dos educadores, praticar a criatividade com intuito de dar respostas diversas, em distintas situações para que possam apresentar decorrências idênticas, e assim, poder complementar que a utilização das novas tecnologias faz parte desta adaptação.

Assim, tendo em vista a inclusão da tecnologia na educação, pode-se dizer que esta poderá ser de grande colaboração quando se tratar da relação entre professores e alunos, visto que o uso da tecnologia torna as aulas mais divertidas e criativas, chamando a atenção dos alunos para os conteúdos ensinados, por meio de ferramentas digitais.

\section{REDE PÚBLICA E AULAS NA MODALIDADE A DISTÂNCIA TOTAL E PARCIAL}

Após diversas discussões, o Conselho Nacional de Educação (2020), publicou a CNE/CP 11/2020, em 3 de agosto de 2020. Tal documento foi homologado parcialmente. As orientações de aulas presenciais e não presenciais, no contexto da pandemia, se resume em breve relato de diagnóstico da Educação Básica: "As escolas da rede pública estadual e municipais terão que realizar adaptações no ambiente escolar para retorno às aulas e que os desafios maiores são em relação à população carente, que sofrem com o difícil acesso à internet, com 
INOVAÇÃO CRIATIVA

NA EDUCAÇÃO BÁSICA

EM TEMPOS DE PANDEMIA

DO COVID-19
Fabiano de Caldas Batista

Fabricio Lima

Maria Geralda de Miranda

Reis Friede

problemas socioeconômico e com a impossibilidade de monitoramento do aprendizado não presencial". (CNE, 2020).

O Instituto Unibanco e Todos pela Educação (2020) apresenta em seu estudo, que a Educação Básica nas redes públicas carece de investimentos na ordem de 30 bilhões para assistir financeiramente estados e municípios, visto que há desafios fiscais e baixa arrecadação no cenário atual.

O trabalho acima referido apresenta debates de suma importância para que as autoridades possibilitem a construção humanitária de uma educação sólida, por meio de políticas públicas eficientes. O desafio para os próximos meses e/ou anos é a adaptação das escolas para possíveis imprevistos, como pandemias. Não é plausível que em pleno século XXI os debates para modernização de atividades sejam encarados apenas como emergencial. É necessário sempre estar aptos aos novos desafios e é inadmissível que os planejamentos estejam voltados exclusivamente para as necessidades de curto prazo, e não enquadrado no contexto de normatização (ALMEIDA; CORDEIRO; PALMEIRA, 2020).

Sabe-se que a garantia de acesso às tecnologias da informação e comunicação, TDIC, vem sendo cultivada no cotidiano dos educadores e alunos, um caminho construtivo e sem volta às novas metodologias de ensino-aprendizagem, haja visto que esta modalidade já é frequente no ensino de nível superior (ALMEIDA; CORDEIRO; PALMEIRA, 2020).

É importante defender o retorno às aulas, porém as alternativas de educação remota não restringem a obrigação da presença do aluno, que diariamente via-se e ouvia-se relatos de pais, que sabiam que seus filhos precisavam frequentar, devido aos benefícios promovidos por programas sociais e políticas públicas, como refeições, educação integral, práticas de esportes e oficinas educativas, o que faz bastante diferença no desenvolvimento acadêmico do educando pobre.

O Plano nacional de Educação, PNE- 2014 a 2024, determina as diretrizes, metas e estratégias para políticas educacionais. Em sua meta 5 , prevê a 
alfabetização de todas as crianças até o $3^{\circ}$ ano do Ensino Fundamental. Já a meta 5.4 prevê desenvolvimento de tecnologias educacionais e de práticas pedagógicas, considerando a diversidade metodológica. A meta 7.12, por seu turno, visa desenvolver tecnologias em todos os níveis de aprendizado, como forma de incentivar práticas inovadoras, por meio de software livre e recursos educacionais abertos (ARRUDA, 2020). O previsto no PNE, descrito em tais metas ainda que iniciado no ano de 2014 até o presente momento encontra-se sem muitos progressos.

Na Pesquisa Nacional de Amostras por Município (PNAD), feita no ano de 2018, observou-se que os estudantes do ensino privado, que possuem acesso à internet, concentram-se principalmente na região Sul (99\%), ao passo que a região Norte se apresenta a menor taxa (95,6\%). Esses dados relativos a alunos da rede pública de ensino também coloca a região Norte com a menor taxa, $(65,4 \%)$ e a maior na região Sudeste, com 90,4\% (ARRUDA, 2020).

Os dados da PNAD revelam que a educação remota no ensino privado, com alunos acima de 10 anos, que não necessita de educação psicomotora, poderá ser realizada. Mas os alunos do ensino público têm dificuldade devido a um maior déficit de acesso à internet.

De acordo com o plano de retorno da educação de São Paulo, SP, lançado pelo decreto $65.061 / 2020$ de julho de 2020, o reinício prevê ocupação máxima, 35\% da sua capacidade. O decreto diz que haverá revezamento dos estudantes semanalmente e definição de protocolo de segurança, conforme previsto no plano. $O$ plano não cita as condições e preferência para escolha dos alunos nesta primeira etapa, nem se serão avaliados de acordo com os indicadores para o IDEB (SÃO PAULO, 2020).

Por suposição, a população que não possui acesso à internet será beneficiada na modalidade presencial, da mesma forma os demais alunos, cuja média comprovada nos dados apresentados pela PNAD no ano de 2018 indicam um 
total de estudantes da Rede Pública de $89,3 \%$ e da rede privada $99,1 \%$. Conclui-se que o previsto no (PRE) atingirá somente $35 \%$ da capacidade (ARRUDA, 2020).

\section{FERRAMENTAS TECNOLÓGICAS E PRÁTICA PEDAGÓGICA}

A escola deve acompanhar as mudanças, adequando-se às necessidades de seus alunos e da sociedade. Deve considerar os recursos da mídia audiovisual, enquanto reflexo da rapidez do mundo moderno, que privilegia a imagem, o som e o movimento. Além das aulas ficarem mais prazerosas, atrai os jovens pela mistura de linguagem, formato e conteúdo e, ainda, significa pluralismo. Os estudantes se identificam com os meios eletrônicos, muito mais que muitos professores. (MEDEIROS; ARAÚJO, 2013).

Tais argumentos reforçam a necessidade das tecnologias na escola, para contribuir com a formação de cidadãos participativos, capazes de compreender e criticar sensivelmente tudo que the é exposto pela mídia. Obviamente, diante de um mundo tão prazeroso, interessante, envolvente e cheio de estímulos, fica difícil a escola competir, utilizando-se de seus métodos e práticas antigas e ultrapassadas.

A persistência em não inovar, em acreditar numa educação tradicional acaba por se constituir em umas das causas de alunos desinteressados, indisciplinados, mal-educados e estressados, por ter que ficar de cinco a seis horas ouvindo, monótonamente, um professor falar. Não se pode negar que a escola, desde os primórdios, sempre procurou acompanhar as mudanças, buscando suprir as necessidades sociais de cada época (FERREIRA, 2014).

As instituições educativas estão entrando, decisivamente, no mundo da tecnologia e o potencial pedagógico dos meios tecnológicos interativos tem sido confirmado por inúmeros estudos, em todo o mundo, destacando especialmente a motivação dos estudantes que fracassam através do uso de métodos tradicionais. A redução da taxa desse fracasso, o estímulo da cognição, o gosto pela leitura e pela 
escrita e a adaptação às capacidades individuais devem ser metas de todas as escolas. (CONTE; MARTINI, 2015).

Segundo Sousa e outros (2016), um ambiente educacional multimídia se caracteriza, pela variedade de meios e de estratégias metodológicas que contém. $\mathrm{O}$ sentido educativo é distinto, o próprio aluno é quem vai construindo sua aprendizagem, assessorado pelo professor, como mediador, e pela tecnologia como instrumento de informação, expressão e criatividade. Pode-se afirmar, portanto, que os meios multimídia, por suas características, facilitam aos docentes a tarefa de atender à diversidade dos alunos.

Quanto ao professor, sugere o autor, que é necessário que as opções que a tecnologia oferece ampliem o horizonte de possibilidades que tem e permitam ensinar de uma maneira melhor. Desta forma, deve considerar a tecnologia como um suporte ao ensino e que possui grandes vantagens diante de outros meios, por seu alto nível de interação. Não se trata apenas de uma ferramenta de apoio, mas sim como ferramenta transformadora dos meios tradicionais de ensino, porque permite gerar processos mais dinâmicos e agradáveis, graças às suas capacidades gráficas, rapidez em cálculos numéricos e facilidades de manipulação e dinamismo, dentre outras (CONTE; MARTINI, 2015).

Se a informática deve ter um papel importante no enriquecimento do trabalho educativo, é indispensável que se tenha clareza de que espécie de educação se deseja promover e como se pode favorecer tal enfoque educativo. Portanto, é necessário incorporar a tecnologia nos processos de ensino-aprendizagem dentro de um planejamento estruturado, consistente com os diversos elementos do currículo e do trabalho educativo, que se desenvolve dentro da sala de aula. Reforça-se que é fundamental, também, que a tecnologia seja incorporada somente quando se mostre mais eficaz ou mais eficiente que outros meios (FERREIRA, 2014).

As crianças da atualidade nascem e crescem sobre os signos das novas tecnologias, assim, o que para os mais velhos é novidade, para elas fazem parte do 
cotidiano, em casa, nos bancos, nos joguinhos. Entretanto, não podem ser consideradas nesta situação somente coisas boas, pois em uma sociedade tão desigual, infelizmente, nem todos têm acesso à tecnologia. (MORAN, 2014).

Conforme Crivellaro e outros (2015), o problema em se ter uma maioria sem acesso à tecnologia se agrava ainda mais quando se percebe que tudo "conspira" para que as pessoas se tornem cada vez mais dependentes da tecnologia. Com certeza, não há como retroceder. Vive-se a sociedade da informática, onde as informações são transmitidas em abundância e rapidez e novas profissões surgem a cada momento. Em consequência, ao lado das grandes mudanças sociais, econômicas, políticas e culturais é necessário aprender a lidar com as tecnologias, a se adaptar a elas e ser capaz de, convivendo com elas, construir conhecimento.

É preciso destacar, entretanto, que o uso dos recursos tecnológicos na educação não deve apresentar-se apenas como máquinas altamente desenvolvidas, que facilitem em grande parte o trabalho educacional, principalmente o burocrático, é necessário que aconteça uma mudança de paradigmas com relação às práticas pedagógicas, caso contrário não será novidade a substituição da máquina de escrever pelo computador (FEITOSA et al., 2014).

Frente a todas essas exigências e necessidades imagina-se que o indivíduo deva ser educado para viver este futuro-presente, de modo que a sociedade use a tecnologia como um bem a serviço do progresso do cidadão e do desenvolvimento democrático, sem se esquecer do caráter humanístico, que envolve as relações entre indivíduos e instituições (LOPES; MELO, 2014).

O professor sozinho não será capaz de resolver o problema, ele necessita de auxílio da escola e da comunidade e, principalmente, dos educandos. Todos devem trabalhar juntos na construção de uma alfabetização tecnológica, que busque uma verdadeira democratização, em termos de acesso aos conhecimentos, inovação e criatividade, em tempos de pandemia e depois. 


\section{CONSIDERAÇÕES FINAIS}

Finalizando este trabalho, pode-se concluir que se vive em meio a uma grande mudança não só em relação ao convívio social, por conta da COVID-19, como também em nossa educação. Professores podem motivar mais seus alunos, através da informática educativa, abandonando velhas metodologias e aceitando a necessidade e importância da tecnologia para a educação. Para isso, é necessário que se comece a produzir mudanças e aceitar a informática educativa como facilitadora do processo de ensino-aprendizagem. Os alunos estão tendo aulas de suas próprias casas, com mais conforto e comodidade, além das aulas serem mais atrativas e distintas das tradicionais, despertando o interesse dos estudantes.

É necessário haver mudanças na formação dos professores, para que se sintam mais seguros e preparados para trabalhar com as tecnologias educacionais. O professor sabe da necessidade e da importância da tecnologia para a educação, ainda mais agora nesse momento de pandemia de COVID-19, mas infelizmente ainda não descobriram como fazer para que ela se torne parte do processo de ensino-aprendizagem.

A alfabetização tecnológica traz novas possibilidades para a vida, auxilia na formação de uma concepção própria de mundo, através da interação e do conhecimento, o que leva à formação de um sujeito ativo e criador de cultura, enfim um meio de expressão e libertação. E é isso que deseja o PNE: estudantes com pensamento crítico e com habilidades para o trabalho. O professor, por sua vez, poderá desenvolver uma sala de aula com momentos criativos e com inovação.

\section{REFERÊNCIAS}

ALMEIDA, Douglas Vieira de; CORDEIRO, Carla Priscilla Barbosa Santos; PALMEIRA, Lana Lisiêr de Lima. O uso das tecnologias digitais da informação e da comunicação (TDIC) como estratégia pedagógica na educação infantil. Brazilian Journal of Development, Curitiba, v. 6, n. 7, p. 42841-42857, jul. 2020. DOI: https://doi.org/10.34117/bjdv6n7-052. Disponível em: 
https://www.brazilianjournals.com/index.php/BRJD/article/view/12575. Acesso em: 26 agosto 2021.

ALMEIDA, Suzana Silveira; LOPES, Bruna Luz De Mattos. Estratégias criativas em EaD na Educação Profissional e Tecnológica. In: III Fórum Mundial de Educação Profissional e Tecnológica, 3., 2015, Recife. 2015. Anais - Mostra de Pôsteres. Recife: IFPE, 2015. Disponível em:

https://www.ifpe.edu.br/anais-fmept-2015/anais-mostra-de-posteres.pdf. Acesso em 26 ago. 2021.

ARRUDA, Eucidio Pimenta. Educação remota emergencial: elementos para políticas públicas na educação brasileira em tempos de Covid-19. EmRede, v. 7, n. 1, p. 257-275, 2020. Disponível em:

https://www.aunirede.org.br/revista/index.php/emrede/article/view/621/575. Acesso em 26 agosto 2021.

CAVALLO, David; SINGER, Helena; GOMES, Alex Sandro; BITTENCOURT, Ig lbert; SILVEIRA, Ismar Frango. Inovação e Criatividade na Educação Básica: Dos conceitos ao ecossistema. Revista Brasileira de Informática na Educação, v. 24, n. 2, 2016. DOI: http://dx.doi.org/10.5753/rbie.2016.24.02.143. Disponível em: https://www.br-ie.org/pub/index.php/rbie/article/view/6504. Acesso em: 26 ago. 2021.

CNE aprova diretrizes para escolas durante a pandemia. Portal MEC, 28 abr. 2020. Disponível em:

http://portal.mec.gov.br/busca-geral/12-noticias/acoes-programas-e-projetos-637152 388/89051-cne-aprova-diretrizes-para-escolas-durante-a-pandemia. Acesso em: 09 out. 2020.

CONSELHO NACIONAL de Educação esclarece principais dúvidas sobre o ensino no país durante pandemia do coronavírus. Portal MEC, 31 mar. 2020. Disponível em:

http://portal.mec.gov.br/busca-geral/12-noticias/acoes-programas-e-projetos-637152 388/87161-conselho-nacional-de-educacao-esclarece-principais-duvidas-sobre-o-en sino-no-pais-durante-pandemia-do-coronavirus. Acesso em: 09 out. 2020.

CONTE, Elaine; MARTINI, Rosa Maria Filippozzi. As Tecnologias na Educação: uma questão somente técnica? Educação \& Realidade, Porto Alegre, v. 40, n. 4, p. 1191-1207, dez. 2015. DOI: https://doi.org/10.1590/2175-623646599. Disponível em: https://www.scielo.br/j/edreal/a/6dtyr69fvxK7bBmCm5H35FQ/?lang=pt. Acesso em: 26 ago. 2021

CRIVELLARO, Débora Barbosa Joaquim; SOUZA, Rosani Aparecida Alves Ribeiro de; GERON, Vera Lúcia Matias Gomes; RACOSKI, Bruna; BRONDANI, Filomena Maria Minetto. Recursos tecnológicos como ferramenta metodológica: vídeo aula no ensino de química. Revista Científica da Faculdade de Educação e Meio 
Ambiente, v. 6, n. 2, p. 92-111, jul-dez, 2015. DOI:

https://doi.org/10.31072/rcf.v6i2.354. Disponível em:

http://www.faema.edu.br/revistas/index.php/Revista-FAEMA/article/view/354/399.

Acesso em 26 ago. 2021.

FEITOSA, Douglas; YOSHIKUNI, Adilson Carlos; LUCAS, Edimilson; ALBERTIN, Alberto Luiz. Um estudo sobre o uso de tecnologias de informação no processo de ensino e aprendizagem. Revista Portuguesa e Brasileira de Gestão, Lisboa, v. 13, n. 4, p. 30-42, 8 out. 2014. Disponível em:

https://bibliotecadigital.fgv.br/ojs/index.php/rbpg/article/view/78698. Acesso em: 26 ago. 2021.

FERREIRA, Maria José Morais Abrantes. Novas tecnologias na sala de aula. 2014. Monografia (Especialização em Fundamentos da Educação: Práticas Pedagógicas Interdisciplinares) - Universidade Estadual da Paraíba, Sousa, 2014. Disponível em:

http://dspace.bc.uepb.edu.br/jspui/bitstream/123456789/6325/1/PDF\%20-\%20Maria \%20Jos\%C3\%A9\%20Morais\%20Abrantes\%20Ferreira.pdf. Acesso em: 09 out. 2020.

INSTITUTO UNIBANCO; Todos pela Educação. COVID-19 IMPACTO FISCAL NA EDUCAÇÃO BÁSICA: O cenário de receitas e despesas nas redes de educação em 2020. São Paulo: [s. n.]: Instituto Unibanco; Todos pela Educação, 2020. Ebook (32 p.). Disponível em:

https://www.todospelaeducacao.org.br/_uploads/_posts/449.pdf?181895214=\&utm_s ource=site-content\&utm_campaign=lancamento. Acesso em: 09 out. 2020.

LOPES, Priscila Malaquias Alves; MELO, Maria de Fátima Aranha de Queiroz e. O uso das tecnologias digitais em educação: seguindo um fenômeno em construção. Psicologia da Educação, São Paulo, n. 38, p. 49-61, jun. 2014. Disponível em:

http://pepsic.bvsalud.org/scielo.php?script=sci_arttext\&pid=S1414-69752014000100 005. Acesso em: 26 ago. 2021.

MORAN, José Manuel. O uso das tecnologias educacionais no ambiente escolar. In: IV Fórum de Gestão Educacional, 4., 24 out. 2014, Rio de Janeiro.

MEDEIROS, Ariane Paula Araújo de; ARAÚJO, Sandra Kelly de. O Uso de Ferramentas Tecnológicas na Sala de Aula. In: XX EGEORN 2013, 20., 2013, Rio Grande do Norte. Encontro Estadual de Geografia do Rio Grande do Norte. Natal: Universidade Federal do Rio Grande do Sul, 2013. p. 1-11. Disponível em: http://arquivos.info.ufrn.br/arquivos/2014057137a0ff198797689d8b25db1a4/O_Uso_ de_Ferramentas_Tecnolgicas_na_Sala_de_Aula.pdf. Acesso em: 26 ago. 2021. 
SÃO PAULO. Decreto $\mathrm{n}^{\circ} \mathbf{6 5 . 0 6 1}$, de 13 de julho de 2020. Dispõe sobre a retomada das aulas e atividades presenciais, no contexto da pandemia de COVID-19, e dá providências correlatas. São Paulo: Assembleia Legislativa do Estado de São Paulo, 13 jul. 2020. Disponível em:

https://www.al.sp.gov.br/repositorio/legislacao/decreto/2020/decreto-65061-13.07.202 0.html. Acesso em: 09 out. 2020.

SILVA, Vera Lúcia de Souza e. Estágio na formação de professores no ensino superior: uma vivência transdisciplinar. In: TORRE, Saturnino de la; PUJOL, Maria Antònia; SILVA, Vera Lúcia de Souza e (coord.). Inovando na sala de aula: instituições transformadoras. Blumenau: Nova Letra, 2013. p.132-148.

SILVEIRA DE ALMEIDA, Suzana. A CRIATIVIDADE INSPIRANDO E MOTIVANDO NA DOCÊNCIA-DISCÊNCIA. In: CIET:EnPED: Congresso Internacional de Educação e Tecnologias/ Encontro de Pesquisadores em Educação a Distância, 2020, São Carlos. Anais do III Congresso Internacional de Educação e Tecnologias/ Encontro de Pesquisadores em Educação a Distância. São Carlos: Universidade Federal de São Carlos, maio 2018. v. 4. p. 1-11. Disponível em: https://cietenped.ufscar.br/submissao/index.php/2018/article/view/611. Acesso em: 09 out. 2020.

SOUSA, Robson Pequeno de; BEZERRA, Carolina Cavalcanti; SILVA, Eliane de Moura; MOITA, Filomena Maria Gonçalves da Silva (org.). Teorias e práticas em tecnologias educacionais. Campina Grande: EDUEPB, 2016. Ebook (227 p.). ISBN: 978-85-787-9299-2e. DOI: https://doi.org/10.7476/9788578793265. Disponível em: http://books.scielo.org/id/fp86k. Acesso em: 26 ago. 2021

SOUZA, Kênia Paulino de Queiroz; PINHO, Maria José de. Criatividade e inovação na escola do século XXI: uma mudança de paradigmas. Revista Ibero-Americana de Estudos em Educação, v. 11, n. 4, p. 1906-1923, 20 dez. 2016. DOI: https://doi.org/10.21723/riaee.v11.n4.6636. Disponível em: https://periodicos.fclar.unesp.br/iberoamericana/article/view/6636. Acesso em: 26 ago. 2021.

ZWIEREWICZ, Marlene. Projetos criativos ecoformadores - PCE: uma via metodológica desde e para o paradigma da complexidade. In: TORRE, Saturnino de la; PUJOL, Maria Antònia; SILVA, Vera Lúcia de Souza e (coord.). Inovando na sala de aula: instituições transformadoras. Blumenau: Nova Letra, 2013. p. 151-175. 